\title{
Hydrogen adsorption and phase transitions in fullerite
}

\author{
Y. Ye, C. C. Ahn, ${ }^{\text {a) }}$ and B. Fultz \\ Division of Engineering and Applied Science, California Institute of Technology, Pasadena, California 91125 \\ J. J. Vajo and J. J. Zinck \\ HRL Laboratories, LLC, Malibu, California 90265
}

(Received 25 May 2000; accepted for publication 1 August 2000)

\begin{abstract}
Hydrogen desorption and adsorption properties of the fullerene materials $\mathrm{C}_{60}, \mathrm{C}_{70}$, and fullerite (a mixture of $\mathrm{C}_{60}$ and $\mathrm{C}_{70}$ ) were measured volumetrically using a Sievert's apparatus. Over several cycles of isotherm measurements at $77 \mathrm{~K}$, the hydrogen storage capacities of one of the fullerite samples increased from an initial value of $0.4 \mathrm{wt} \%$ for the first cycle to a capacity of $4.4 \mathrm{wt} \%$ for the fourth cycle. Correspondingly, the surface area of this sample increased from 0.9 to $11 \mathrm{~m}^{2} / \mathrm{g}$, and there were changes in its x-ray powder diffraction pattern. In comparison, two other fullerite samples, prepared by a different procedure showed no such behavior. Pure $\mathrm{C}_{60}$ and pure $\mathrm{C}_{70}$ were also cycled and exhibited small and constant capacities of 0.7 and $0.33 \mathrm{wt} \%$, respectively, as a function of number of cycles. The enhanced storage capacity of fullerite material is tentatively attributed to the presence of $\mathrm{C}_{60}$ oxide. (C) 2000 American Institute of Physics.
\end{abstract}

[S0003-6951(00)03039-4]

There has been widespread interest in recent claims that certain carbon structures such as nanofibers and nanotubes can store much more hydrogen than conventional forms of carbon. ${ }^{1-3}$ Crystalline fcc $\mathrm{C}_{60}$, however, has been observed to absorb $\mathrm{H}_{2}$ in octahedral interstices, providing a small storage capacity of only $0.28 \mathrm{wt} \%$ at $40{ }^{\circ} \mathrm{C}^{4}$

In this letter, we present the results of studies on the sorption of $\mathrm{H}_{2}$ by fullerenes. In the fullerene family, the closed-cage, nearly spherical $\mathrm{C}_{60}$ and the ellipsoidal rugbyball-shaped $\mathrm{C}_{70}$ are the most stable molecules ${ }^{5}$ and are thus relatively abundant. We performed measurements on pure $\mathrm{C}_{60}$, pure $\mathrm{C}_{70}$, and three sets of a mixture of these two commonly referred to as "fullerite." We report a surprising increase in the amount of $\mathrm{H}_{2}$ adsorption for one of these fullerites. The isotherms show the characteristics of physisorption, so we note that this work is different from hydrogenation studies of fullerenes ${ }^{6,7}$ involving chemisorption of atomic hydrogen.

Several different commercially available fullerene samples were obtained from Alfa Aesar and MER Corp. All these fullerenes were made by a carbon arc discharge in helium (Hoffman-Dratchshermer method). The carbon soot was then treated in toluene. The fullerite is soluble in toluene at the limit of $2 \mathrm{~g} / \mathrm{l}$ and for the first fullerite sample (denoted fullerite No. 1) from MER Corp. and obtained in 1992, the solution was spread onto a teflon tray and evaporated at room temperature. For the second fullerite sample from Alfa Aesar (denoted fullerite No. 2) and obtained in 1999, the precipitate from the toluene solution was obtained after slow evaporation of the toluene. The precipitate was then washed with petroleum ether and underwent drying to remove the rest of the solvent. A third sample of fullerite was obtained from MER in 1999 (denoted as fullerite No. 3) and was processed similarly to fullerite No. 2. All fullerite samples typically contained about $75 \% \mathrm{C}_{60}, 22 \% \mathrm{C}_{70}$, with the bal-

${ }^{a)}$ Electronic mail: cca@caltech.edu ance being higher fullerene molecules. The pure $\mathrm{C}_{60}\left(\right.$ or $\mathrm{C}_{70}$ ) fullerenes were obtained by chromatographic purification, and the purity was $99.9 \%$ for $\mathrm{C}_{60}$ and $\sim 98 \%$ for $\mathrm{C}_{70}$.

Desorption and some adsorption isotherms were measured with a computer-controlled Sieverts' apparatus (i.e., a volumetric system for quantitative measurement of gas absorption and desorption by solids) on $600 \mathrm{mg}$ samples at 300 and $77 \mathrm{~K}$. After vacuum degassing at $200^{\circ} \mathrm{C}$ for $10 \mathrm{~h}$, the measurement temperature was attained and hydrogen gas of 99.9999\% purity was admitted into the reactor to a maximum pressure of about 120 bar. This pressure was maintained for $15 \mathrm{~h}$ to allow the adsorption to equilibrate and to check for leaks in the system. To correct for instrumental effects, identical volumetric measurements were performed on an empty reactor after each sample measurement. This procedure was used for every adsorption/desorption cycle, even when multiple cycles were taken on the same sample.

Surface area was measured by the Micromeritics Corp. by Brunauer-Emmett-Teller (BET) surface area analysis using nitrogen gas. X-ray powder diffractometry was performed on as-received and cycled samples, using an Inel CPS-120 powder diffractometer using $\mathrm{Co}_{\alpha}$ radiation. High performance liquid chromatography (HPLC) measurements were performed at MER Corp.

Table I summarizes the results from the hydrogen adsorption/desorption and BET measurements. The hydrogen storage capacities of pure $\mathrm{C}_{60}$ and $\mathrm{C}_{70}$ are reproducible and are consistent with results of others. ${ }^{4}$ On the other hand, fullerite No. 1 exhibited unusual isotherm behavior. As shown in Fig. 1(a), the capacity during the first desorption run on the as-received fullerite No. 1 (labeled 1st run) is small, comparable to the capacity of pure $\mathrm{C}_{60}$ or pure $\mathrm{C}_{70}$. The capacity then increased dramatically with each subsequent isotherm cycle. In the fourth cycle (labeled 4th run), it reached a maximum of $4.4 \mathrm{wt} \%$ at 120 bar at $77 \mathrm{~K}$. This value is consistent with complete $\mathrm{H}_{2}$ adsorption onto the surfaces of the fullerene molecules, assuming that $\mathrm{H}_{2}$ molecules 
TABLE I. $\mathrm{H}_{2}$ storage capacities and BET surface areas of fullerenes.

\begin{tabular}{cccccccc}
\hline \hline & & \multicolumn{2}{c}{$\begin{array}{c}\mathrm{H}_{2} \mathrm{wt} \% \\
(300 \mathrm{~K})\end{array}$} & \multicolumn{2}{c}{$\begin{array}{c}\mathrm{H}_{2} \mathrm{wt} \% \\
(77 \mathrm{~K})\end{array}$} & \multicolumn{2}{c}{$\begin{array}{c}\text { Surface area } \\
\left(\mathrm{m}^{2} / \mathrm{g}\right)\end{array}$} \\
\cline { 3 - 8 } Sample & $\begin{array}{c}\text { Composition } \\
(\text { HPLC })\end{array}$ & $\mathrm{Abs}$ & $\mathrm{Des}$ & $\mathrm{Abs}$ & $\mathrm{Des}$ & As rec. & Cycled \\
\hline $\mathrm{C}_{60}$ & $99.9+\%$ & 0.07 & 0.08 & 0.83 & 0.70 & & \\
$\mathrm{C}_{70}$ & $98+\%$ & 0.12 & 0.12 & & 0.33 & & \\
Fullerite & $75 \% \mathrm{C}_{60} 22 \% \mathrm{C}_{70}$ & & & 4.00 & $0.58-4.38$ & 0.9 & \\
$\quad$ No.1 & $1.5 \% \mathrm{C}_{60}$ oxides & & & & & & \\
Fullerite & $75 \% \mathrm{C}_{60} 22 \% \mathrm{C}_{70}$ & & & $0.38-0.60$ & $0.80-0.99$ & 4 & \\
$\quad$ No.2 & $0.2 \% \mathrm{C}_{60}$ oxides & & & & & & \\
Fullerite & $77 \% \mathrm{C}_{60} 21 \% \mathrm{C}_{70}$ & & & & $0.2-0.3$ & & \\
No.3 & $0.6 \% \mathrm{C}_{60}$ oxides & & & & & & \\
\hline \hline
\end{tabular}

of diameter $3.5 \AA$ form a close-packed shell around each fullerene molecule. This implies that further improvements in the hydrogen adsorption capacities of mixed fullerite materials may be difficult to achieve. At the fifth cycle, the capacity decreased to about $2.5 \mathrm{wt} \%$. Samples of the same material were analyzed for their surface area by the BET method. The BET surface area changed from $0.9 \mathrm{~m}^{2} / \mathrm{g}$ for the as-received fullerite No. 1 to $11 \mathrm{~m}^{2} / \mathrm{g}$ after five isotherm cycles.

To verify these results, we tested a second sample of fullerite No. 1, and obtained the same isotherm behavior as a function of cycle number. These results are presented in Fig. 1(b). A total of seven cycles was performed on the second sample of fullerite No. 1 and cycles five to seven showed identical isotherm traces. On the other hand, a similar Sievert's apparatus was used to measure one point of the
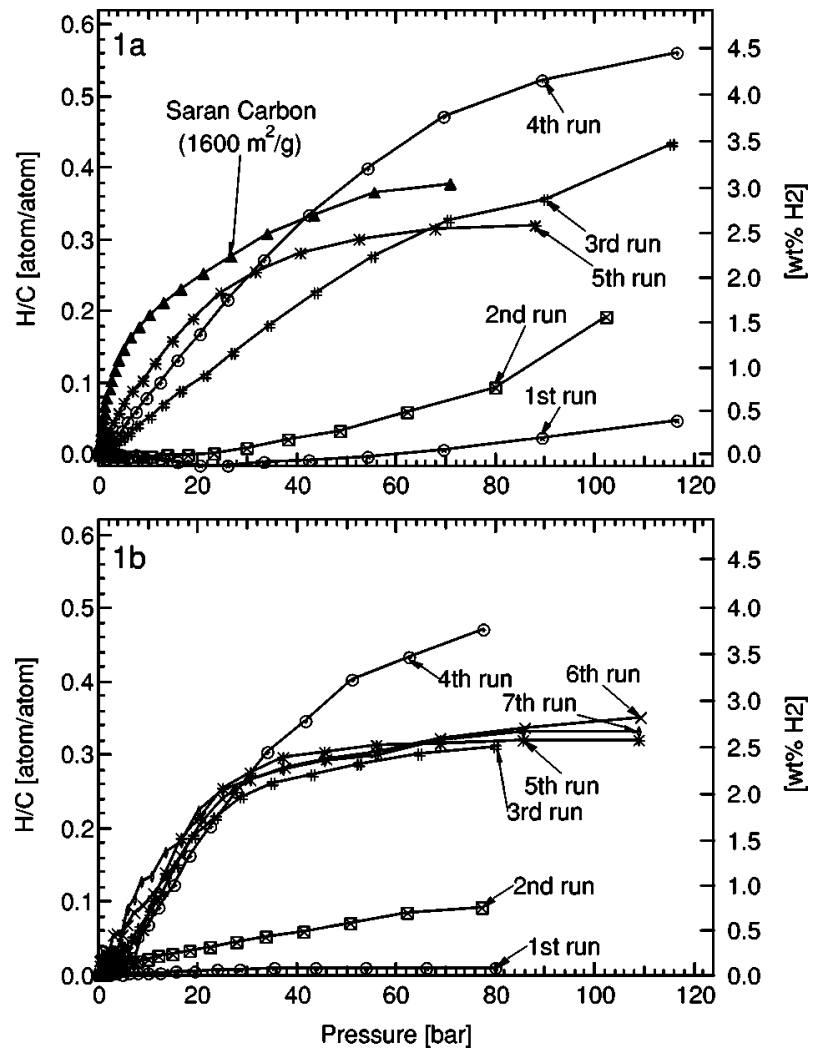

FIG. 1. Desorption isotherms of composition vs pressure at $77 \mathrm{~K}$ for two different samples of fullerite No. 1 of $\mathrm{C}_{60}-\mathrm{C}_{70}$ fullerite materials. The upper set includes a trace for Saran carbon. The lower set shows identical isotherm

$\begin{array}{ll}\text { behavior as a function of adsorption/desorption cycle number. } & \text { FIG. 2. X-ray diffraction patterns of fullerenes. } \\ \text { Downloaded } 12 \text { Jan } 2006 \text { to 131.215.240.9. Redistribution subject to AIP license or copyright, see http://apl.aip.org/apl/copy }\end{array}$ isotherm at $77 \mathrm{~K}$ at about 50 bar, but this measurement showed only $0.05 \mathrm{wt} \%$ hydrogen sorption. Sample handling procedures were similar although not identical, and we are still investigating this discrepancy in these measurements. Fullerite No. 2 behaved similarly to the samples of pure $C_{60}$ or pure $\mathrm{C}_{70}$ and showed only small differences as a function of cycle number as shown in Table I. Fullerite No. 3 which was obtained recently from MER and used as a control sample, showed even smaller desorption capacities than fullerite No. 2 at 77 K. For comparison, we also measured the hydrogen desorption of high surface area saran carbon. ${ }^{8}$

HPLC measurements of these materials showed only slight variations in the $\mathrm{C}_{60}-\mathrm{C}_{70}$ ratio. Therefore, we believe that the important difference between fullerite Nos. 1, 2, and 3 , is the amount of oxidized $\mathrm{C}_{60}$ found in as-received fullerite No. 1. The oxidized $\mathrm{C}_{60}$ accounts for $\sim 2 \%$ of the asreceived fullerite. The oxidized component was absent in the material after it had been cycled with $\mathrm{H}_{2}$ gas. The oxidation of fullerite No. 1 occurred presumably over the 7 year time span from its synthesis to the time the desorption experiments were performed.

$\mathrm{X}$-ray diffraction patterns of the samples are presented in Fig. 2. The diffraction pattern of the pure $\mathrm{C}_{60}$ is that of the expected fcc structure with $a=14.2 \AA{ }^{9}{ }^{9}$ For fullerite samples, the broad peaks between the $\mathrm{C}_{60}$ (220) and (311)

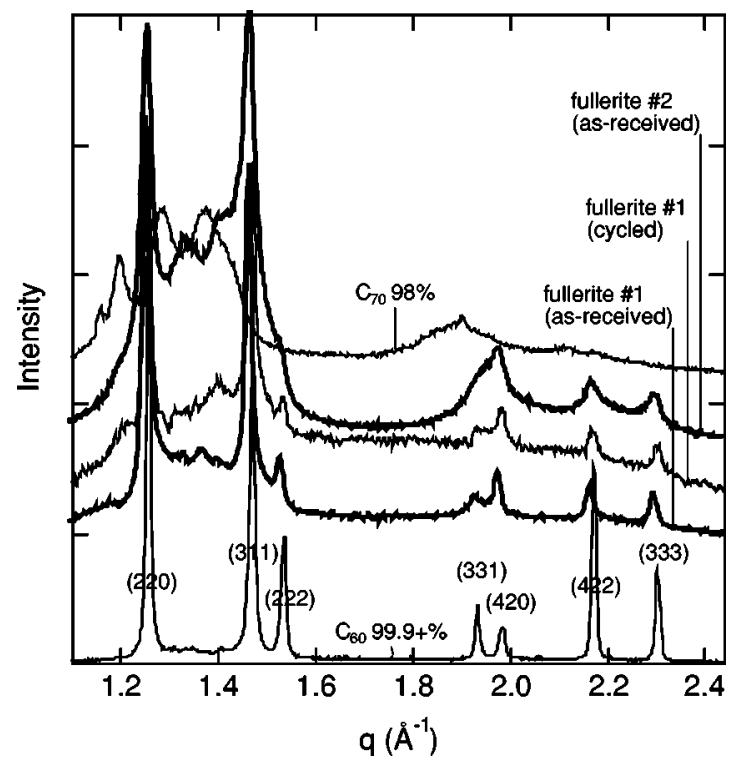

FIG. 2. X-ray diffraction patterns of fullerenes. or copyright, see http://apl.aip.org/apl/copyright.jsp 
peaks are contributed by phases of $\mathrm{C}_{70}$. The structural phase transitions and orientational ordering in $\mathrm{C}_{70}$ at different temperature and pressure have been studied extensively for the past decade. ${ }^{10-12}$ Although there is still no agreement about the details of the structures, there is general agreement as to the temperatures of the phase transitions. Five phases have been observed, including face-centered-cubic (fcc), ${ }^{12}$ rhombohedral, ${ }^{10}$ ideal hexagonal-close-packed (hcp) $(c / a$ $=1.63),{ }^{12,10}$ deformed hcp $(c / a=1.82),{ }^{13,14}$ and a monoclinic phase. ${ }^{10}$ Some phase transitions occur over a wide temperature range and exhibit large hysteresis which depends on the thermal history of the sample. ${ }^{10,15}$

Figure 2 shows that the diffraction pattern of $\mathrm{C}_{70}$ in fullerite No. 1 changed after several isotherm cycles. Due to the broadening and the low intensity of the $\mathrm{C}_{70}$ peaks, it is not possible for us to identify reliably the phases in the samples. However, the change in the diffraction pattern from $q=1.3$ to $1.4 \AA^{-1}$ indicates that some parts of the material have undergone a phase change after hydrogen cycling. Furthermore, the diffraction peaks from the $\mathrm{C}_{60}$ in fullerite No. 1 became sharper after cycling. On the other hand, the $\mathrm{C}_{60}$ diffraction peaks from fullerite No. 2 sharpened after cycling, but there was little change in the region of $q$ $=1.3-1.4 \AA^{-1}$.

We believe the high hydrogen adsorption of fullerite No. 1 is a consequence of a hydrogen-induced structural transition in the fullerite much like that reported for carbon singlewalled nanotubes. ${ }^{8}$ Three energies are involved. One is the energy of adsorption of the $\mathrm{H}_{2}$ molecule on the surface of the carbon. For SWNTs this energy for hydrogen physisorption was approximately $-38 \mathrm{meV}$ (characteristic of adsorption on graphite), and we expect this adsorption energy to be similar for hydrogen adsorption on $\mathrm{C}_{60}$ and $\mathrm{C}_{70}$. Second is the van der Waals energy of cohesion of the $\mathrm{C}_{60}$ and $\mathrm{C}_{70}$ crystals. Evidently these van der Waals interactions in pure $\mathrm{C}_{60}$ and $\mathrm{C}_{70}$ are sufficiently strong so that the crystals remain intact and the hydrogen sorption is limited to absorption in interstitial sites and adsorption on the relatively few surface sites. The third "energy" is the chemical potential of the hydrogen molecules, which increases with hydrogen gas pressure. It is possible to reduce this contribution to the total free energy by surface adsorption of some of the hydrogen. The phase transition in the SWNT material was driven by this reduction in hydrogen chemical potential during physisorption, which was sufficient to overcome the van der Waals attraction between the tubes in a rope, separating them into individual tubes with a large surface area for hydrogen adsorption.

Evidently this phase transition does not occur in the samples of pure $\mathrm{C}_{60}$ or $\mathrm{C}_{70}$, and these materials remain intact because their van der Waals attractions are strong. The van der Waals interaction and other electron-electron correlation effects responsible for cohesion decrease rapidly with distance, however. Poor crystallinity in the $\mathrm{C}_{60}-\mathrm{C}_{70}$ fullerite No. 1, perhaps induced by the phase transitions in the $\mathrm{C}_{70}$ regions, or by oxidation, could reduce the cohesive energy of the fullerite so that hydrogen adsorption could occur with structural dissociation. The shapes of the isotherms of fullerite No. 1 were not reproducible until after the fifth cycle, indicating that its cohesive energy was altered after a hydro- gen sorption/desorption cycle. The $\mathrm{x}$-ray diffraction patterns of fullerite No. 1 also showed a change in structure, and this sample also showed an unusual increase in surface area (although the increase in surface area is itself too small to account for significant physisorption).

We suggest two possible reasons for lower cohesive energy of fullerite No. 1 than fullerite No. 2. The microstructural distribution of $\mathrm{C}_{60}, \mathrm{C}_{70}$, and higher fullerene molecules may differ owing to differences in material preparation, causing differences in the structural transformations under temperature and hydrogen pressure. Differences in the breadth of the fcc $\mathrm{C}_{60}$ peaks in the diffraction patterns are evidence for a microstructural difference between the fullerites Nos. 1 and 2, and these peaks underwent an observable change after fullerite No. 1 was cycled. The cohesive energy could also differ between fullerite Nos. 1 and 2 because of the more extensive oxidation of the $\mathrm{C}_{60}$ in fullerite No. 1 . The cyclic exposure to hydrogen gas reduced the oxidized $\mathrm{C}_{60}$ in fullerite No. 1, perhaps causing an increase of its cohesive energy and the observed reduction of hydrogen storage capacity after four cycles. The $\mathrm{C}_{60}$ oxide was absent after five cycles, but the hydrogen adsorption capacity of fullerite No. 1 remained large, so we cannot attribute all of the difference between fullerite samples to oxidation. We do note, however, that oxidation has been observed to influence structural phase transitions in pure $\mathrm{C}_{60}{ }^{16}$ and mechanical properties of $\mathrm{C}_{60} \cdot{ }^{17}$

This work was supported by DOE through Basic Energy Sciences Grant No. DE-FG03-00ER15035.

${ }^{1}$ A. C. Dillon, K. M. Jones, T. A. Bekkedahl, C. H. Kiang, D. S. Bethune, and M. J. Heben, Nature (London) 386, 377 (1997).

${ }^{2}$ A. Chambers, C. Park, R. T. K. Baker, and N. M. Rodriguez, J. Phys. Chem. B 102, 4253 (1998).

${ }^{3}$ C. Liu, Y. Y. Fan, M. Liu, H. T. Cong, H. M. Cheng, and M. S. Dresselhaus, Science 286, 1127 (1999).

${ }^{4}$ X. Lu, R. O. Loutfy, E. Veksler, and J. C. Wang, in Symposium on Recent Advances in the Chemistry and Physics of Fullerenes and Related Materials, edited by K. M. Kadish and R. S. Ruoff (Electrochemical Society, Pennington, NJ, 1998).

${ }^{5}$ H. W. Kroto, J. R. Heath, S. C. O'Brien, R. F. Curl, and R. E. Smalley, Nature (London) 318, 162 (1985).

${ }^{6}$ E. L. Brosha, J. Davey, F. H. Garzon, and S. Gottesfeld, J. Mater. Res. 14, 2138 (1999).

${ }^{7}$ P. A. Bruhwiler, S. Andersson, M. Dippel, N. Martensson, P. A. Demirev, and B. U. R. Sundqvist, Chem. Phys. Lett. 214, 45 (1993).

${ }^{8}$ Y. Ye, C. C. Ahn, C. Witham, B. Fultz, J. Liu, A. G. Rinzler, D. Colbert, K. A. Smith, and R. E. Smalley, Appl. Phys. Lett. 74, 2307 (1999).

${ }^{9}$ P. W. Stephens, L. Mihaly, P. Lee, R. Whetten, S. M. Huang, R. Kaner, F. Deiderich, and K. Holczer, Nature (London) 351, 632 (1991).

${ }^{10}$ A. R. McGhie, J. E. Fischer, P. W. Stephens, R. L. Cappelletti, D. A. Neumann, W. H. Mueller, H. Mohn, and H. U. ter Meer, Phys. Rev. B 49, 12614 (1994).

${ }^{11}$ G. van Tendeloo, S. Amelinckx, M. A. Verheijen, P. H. M. van Loosdrecht, and G. Meijer, Phys. Rev. Lett. 69, 1065 (1992).

${ }^{12}$ G. B. M. Vaughan, P. A. Heiney, J. E. Fischer, D. E. Luzzi, D. A. Rickettsfoot, A. R. McGhie, Y. W. Hui, A. L. Smith, D. E. Cox, W. J. Romanow, B. H. Allen, N. Coustel, J. P. McCauley, and A. B. Smith, III, Science 254, 1350 (1991).

${ }^{13}$ E. Blanc, H. B. Burgi, R. Restori, D. Schwarzenbach, and P. Ochsenbein, Europhys. Lett. 33, 205 (1996).

${ }^{14}$ S. van Smaalen, V. Petricek, J. L. de Boer, M. Dusek, M. A. Verheijen, and G. Meijer, Chem. Phys. Lett. 223, 323 (1994).

${ }^{15}$ J. E. Fischer and P. A. Heiney, J. Phys. Chem. Solids 54, 1725 (1993).

${ }^{16}$ F. Yan and Y. Wang, J. Phys. Chem. Solids 61, 1003 (2000).

${ }^{17}$ I. Manika, J. Manika, and J. Kalnacs, Carbon 36, 641 (1998). 